\title{
Textiloma: A Case Report of Rectal Expulsion
}

\author{
Issam Yazough ${ }^{1}$, Jean Marie Ovungu ${ }^{2}$, Pierlesky Elion Ossibi ${ }^{1}$, Franck Mvumbi ${ }^{2}$, Said AitLaalim ${ }^{1}$, \\ Youssef Lamrani' ${ }^{2}$ Imane Toughrai ${ }^{1}$, Karim Ibn Majdoub', Khalid Mazaz ${ }^{1}$
}

\author{
${ }^{1}$ Department of Visceral Surgery, Hassan II University Hospital, Fez, Morocco \\ ${ }^{2}$ Department of Radiology, Hassan II Teaching Hospital, Fez, Morocco \\ Email: ^issam.yazough@gmail.com
}

How to cite this paper: Yazough, I., Ovungu, J.M., Ossibi, P.E., Mvumbi, F., Ait Laalim, S., Lamrani, Y., Toughrai, I., Ibn Majdoub, K. and Mazaz, K. (2017) Textiloma: A Case Report of Rectal Expulsion. Surgical Science, 8, 82-85. https://doi.org/10.4236/ss.2017.82010

Received: March 4, 2016

Accepted: January 19, 2017

Published: January 22, 2017

Copyright $\odot 2017$ by authors and Scientific Research Publishing Inc. This work is licensed under the Creative Commons Attribution International License (CC BY 4.0).

http://creativecommons.org/licenses/by/4.0/

\begin{abstract}
Textiloma is a rare pathological entity which can possibly complicate any surgery. Its incidence, reported in literature, is estimated between $1 / 1000$ and $1 / 15,000$. Abdominal and gynecological surgeries are responsible for the vast of majority of intra abdominal textiloma. Very few cases of spontaneous rectal expulsion of textiloma have been reported. We report the case of rectal expulsion of textiloma in a 26-year-old female who had undergone a $\mathrm{C}$ section for dynamic dystocia a year prior to her admission.
\end{abstract}

\section{Keywords}

Textilome, Rectal Expulsion, Colonoscopy

\section{Introduction}

Textiloma or retained surgical foreign body is a rare, medically related error, potentially life threatening, which can complicate considerably any type of surgery. Unfortunately, it often leads to additional and repeated surgery hence associated with higher rates of morbidity and mortality. On the other hand, there are very few cases relating to spontaneous rectal expulsion of textiloma or other retained surgical foreign bodies [1]. Thus we hereby report a case of textiloma expelled in faeces in a 26-year-old female with previous medical history of Csection for dynamic dystocia a year prior to her admission.

\section{Case Report}

Patient, 26-year-old mother who underwent a C-section a year prior to her admission for dynamic dystocia with uneventful immediate postoperative recovery. Six months later, patient presented with generalized abdominal pain and a painful swelling in the right lower quadrant. Clinical examination found a visibly sick afebrile patient, stable vital signs, with abdominal palpation revealing a ten- 
der mobile mass in the right iliac fossa measuring about $10 \mathrm{~cm}$. Abdominal scan showed a tumor-like lesion of the caecum (Figure 1(a)), without signs of lymphatic invasion nor metastatic disease. Colonoscopy was performed revealing a foreign body at the last ileal loop (Figure 1(b)) with failed endoscopic extraction. Hence, patient was scheduled for elective surgery. However, the clinical course was marked a few days after endoscopy by a spontaneous rectal expulsion of a green surgical towel (Figure 1(c)). The patient was closely monitored for 48 hours with physical examination showing no signs of peritoneal irritation and laboratory tests unremarkable. During a six month follow up, regular visits also remained unremarkable.

\section{Discussion}

The term "textiloma" commonly refers to a retained surgical foreign body (usually a textile material in the form of gauze or sponge) unintentionally left behind after a procedure. Leaving behind foreign bodies in the peritoneal cavity constitutes an unfortunate medical error with frequency reported in literature ranging from $1 / 1000$ to $1 / 15,000$ cases [2].

Digestive and gynecological operations account for between $60 \%$ and $74 \%$ of cases of intra-abdominal textilomas [3] [4] [5]. Elective surgery often responsible in $71 \%$ of reported cases [4]. In $60 \%$ of cases recorded in literature, the textiloma is a large surgical towel or rarely many towels left behind mistakenly at one or several operating fields [4].

From a pathophysiological standpoint, textilomas elicit two types of inflammatory response. The first is one of aseptic fibrosis leading to the formation of adhesions and encapsulations; resulting in foreign body granuloma, setting insidiously without showing any clinical symptoms. The second is rather an acute

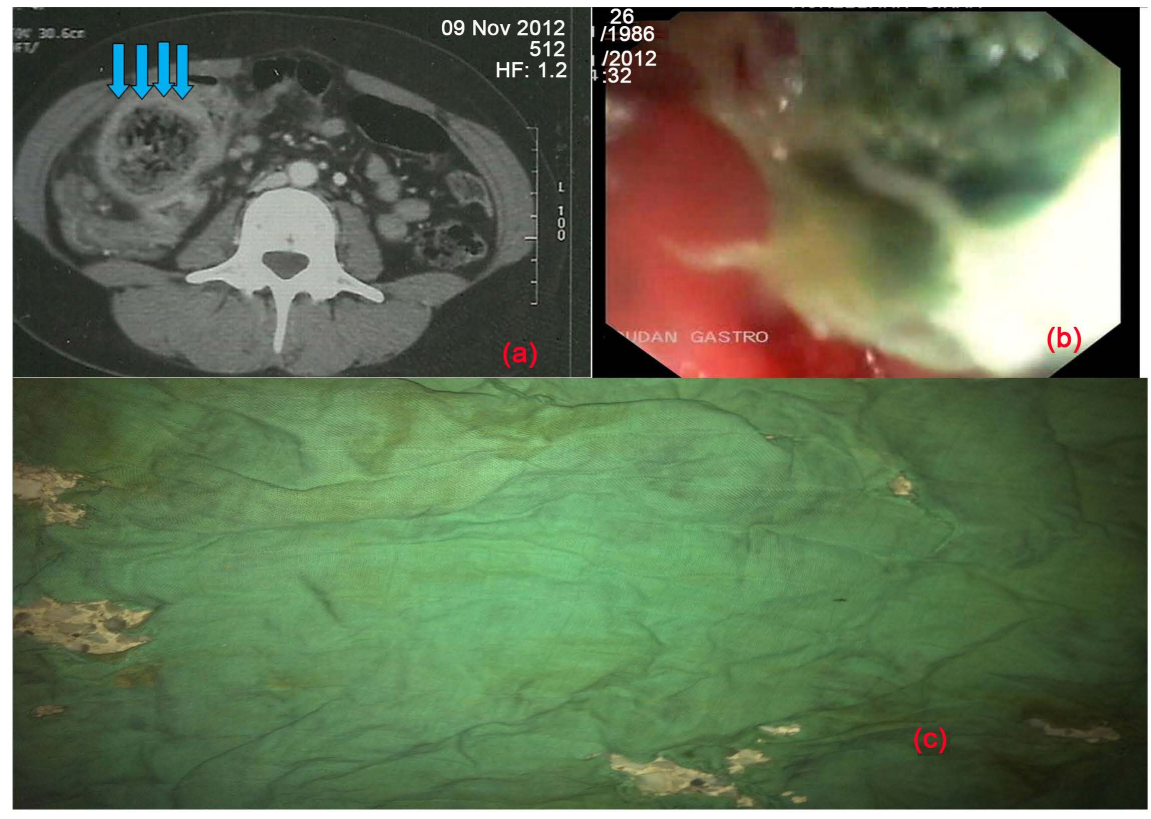

Figure 1. (a) CT scan showing a right iliac fossamass; (b) Endoscopic image of textiloma; (c) Textiloma after rectal expulsion. 
exudative manifestation leading to abscess formation with or without secondary bacterial invasion. In the latter, it may presents as abdominal pain, a mass, bowel obstruction, gastrointestinal bleeding, abdominal infection or even peritonitis and in some cases forming fistula with surrounding organs [6].

Retained foreign body detection timeline is variable, ranging from days to several years after surgery [7]. Generally, several clinical presentations have been described previously: abdominal infection, bowel obstruction, GI bleeding, pseudo-tumor forms, fistula forming cases and even asymptomatic ones with incidental findings [4] [5].

Migration of textiloma in the intestinal lumen is considered a rare complication and occurs as a result of inflammation of the intestinal wall leading to necrosis [1]. Few cases have been reported in the literature: a case involving intestinal lumen migration recorded in Japan [8] with Zantvoord et al. [1] noting 65 cases in total including one of theirs.

The most common site of impaction is the intestine (75\%), and most cases (95.3\%) underwent laparotomy to remove textiloma [1]. After complete migration in the intestine, textiloma usually ends up in the terminal ileum, as was the case in our patient where it often leads to small bowel obstruction [9]. On the other hand, cases of spontaneous rectal expulsion of textiloma as in our patient are rarely described [1].

Despite technological advancement in diagnostic imaging the exact location of migrated textiloma is hardly determined by imaging [10]. In our patient, textiloma mimicked a tumor like lesion of the caecum on abdominal CT.

However, textilomas diagnosed late or after complication, present an inherent higher risk with mortality varying between $11 \%$ and $35 \%$ [3]. Some textilomas have been expelled without tissue damage by natural means. [4]

\section{Conclusions}

Textiloma is a very rare but serious complication of surgery due to its potential clinical consequences and legal implications. Several circumstances of discovery of retained surgical sponge have been described, yet spontaneous rectal expulsion of textiloma remains exceptional.

The surgical team is not immune to the ethical implications of this medical error that can sometimes jeopardize the life of patients.

Prevention is practically the best way to reduce its incidence. The policy of prevention could be enforced by the surgeon himself during swab counts or through the use of radiological markers and other adjunct technology.

\section{References}

[1] Zantvoord, Y., van der Weiden, R.M. and van Hooff, M.H. (2008) Transmural Migration of Retained Surgical Sponges: A Systematic Review. Obstetrical \& Gynecological Survey, 63, 465-471. https://doi.org/10.1097/OGX.0b013e318173538e

[2] Rappaport, W. and Haynes, K. (1990) The Retained Surgical Sponge Following Intraabdominal Surgery. Archives of Surgery, 125, 405-407. 
https://doi.org/10.1001/archsurg.1990.01410150127025

[3] Le Neel, J.C., De Cussac, J.B., Dupas, B., Letessier, E., Borde, L., Eloufir, M. and Armstrong, O. (1994-1995) Textiloma. A Propos of 25 Cases and Review of the Literature. Chirurgie, 120, 272-277.

[4] Hajji, A., Abbar, M., Bouchama, R. and Moulay, A. (1998) Intraperitoneal textiloma. Apropos of 5 Cases. Journal de Chirurgie, 125, 353-357.

[5] Guiard, J.M., Bonnet, J.C., Boutin, J.P., Plane, D., Guilleux, M.H. and Delorme, G. (1988) "Textiloma": X-Ray Computed Tomographic Aspect. Apropos of a Case. Annales de Radiologie, 31, 49-52.

[6] Choi, B.I., Kim, S.H., Yu, E.S., Chung, H.S., Han, M.C. and Kim, C.W. (1988) Retained Surgical Sponge: Diagnosis with CT and Sonography. American Journal of Roentgenology, 150, 1047-1050. https://doi.org/10.2214/ajr.150.5.1047

[7] Hesp, W.L. and Goris, R.J.A. (1983) Cyste per Magma Abdominales. Acta chirurgica Belgica, 83, 416-419.

[8] Ko, K., Fujioka, S., Kato, K., Machiki, Y., Hashimoto, M. and Ishikawa, A. (2000) A Case Report of a Retained Gauze Sponge in the Abdomen with Massive Bleeding from the Rectum. The Japanese Journal of Gastroenterological Surgery, 33, 17141718. https://doi.org/10.5833/ijgs.33.1714

[9] Silva, C.S., Caetano, M.R., Silva, E.A., Falco, L. and Murta, E.F. (2001) Complete Migration of Retained Surgical Sponge into Ileum without Sign of Open Intestinal Wall. Archives of Gynecology and Obstetrics, 265, 103-104. https://doi.org/10.1007/s004040000141

[10] Dux, M., Ganten, M., Lubienski, A. and Grenacher, L (2002) Retained Surgical Sponge with Migration into the Duodenum and Persistent Duodenal Fistula. European Radiology, 12, 74-77.

\section{Submit or recommend next manuscript to SCIRP and we will provide best service for you:}

Accepting pre-submission inquiries through Email, Facebook, LinkedIn, Twitter, etc. A wide selection of journals (inclusive of 9 subjects, more than 200 journals)

Providing 24-hour high-quality service

User-friendly online submission system

Fair and swift peer-review system

Efficient typesetting and proofreading procedure

Display of the result of downloads and visits, as well as the number of cited articles

Maximum dissemination of your research work

Submit your manuscript at: http://papersubmission.scirp.org/

Or contact ss@scirp.org 